\title{
Correction to: Synthesis, characterization, and intraperitoneal biochemical studies of zinc oxide nanoparticles in Rattus norvegicus
}

\author{
Abbas Rahdar ${ }^{1} \cdot$ Mohammad Reza Hajinezhad $^{2} \cdot$ Vishnu Sankar Sivasankarapillai $^{3} \cdot$ Faezeh Askari $^{1} \cdot$ Mehdi Noura $^{1}$. \\ George Z. Kyzas ${ }^{4}$
}

Published online: 15 May 2020

๑) Springer-Verlag GmbH Germany, part of Springer Nature 2020

Correction to: Applied Physics A (2020) 126:347

https://doi.org/10.1007/s00339-020-03535-0

In the original publication of the article, the third author's name and affiliation were incorrect. The correct name and affiliation appear as below.

Publisher's Note Springer Nature remains neutral with regard to jurisdictional claims in published maps and institutional affiliations.

The original article can be found online at https://doi.org/10.1007/ s00339-020-03535-0.

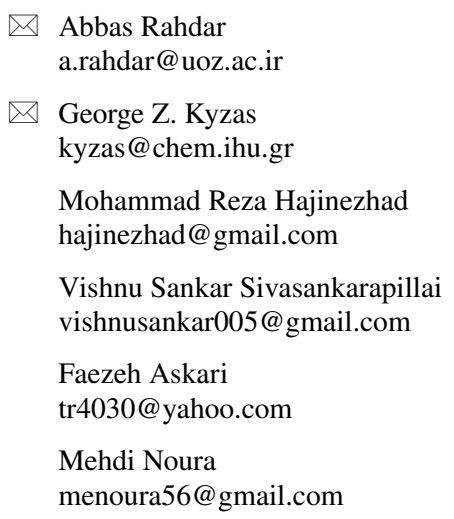

1 Department of Physics, University of Zabol, P. O. Box. 35856-98613, Zabol, Islamic Republic of Iran

2 Basic Veterinary Science Department, Veterinary Faculty, University of Zabol, Zabol, Iran

3 Department of Chemistry, NSS Hindu College, Changanacherry 686102, Kerala, India

4 Department of Chemistry, International Hellenic University, Kavala, Greece 